\title{
Tomato spotted wilt virus Can Infect Resistant Tomato when Western Flower Thrips Inoculate Blossoms
}

\author{
J. L. Houle and G. G. Kennedy, ${ }^{\dagger}$ Department of Entomology and Plant Pathology, North Carolina State University, Raleigh, 27695-7630
}

\begin{abstract}
Tomato spotted wilt is a major disease of crops worldwide. Resistant cultivars carrying the $\mathrm{Sw}-5$ allele for resistance to tomato spotted wilt disease (TSW) provide the most effective control method in tomato (Solanum lycopersicum). However, infections of fruit on Sw-5+ tomato plants suggest the virus resistance may not be fully expressed in blossoms or developing fruit. The objective of this study was to determine if the thrips vector, the western flower thrips (Frankliniella occidentalis), can transmit non-resistance breaking Tomato spotted wilt virus (TSWV) isolates when confined to blossoms on plants with and without the Sw-5 resistance allele. Twenty-one percent of $33 \mathrm{Sw}-5+$ plants inoculated by adult thrips feeding on blossom clusters or small fruit developed infections in the reproductive tissue, whereas

$68 \%$ of 25 Sw-5- plants developed infections. Systemic infections also occurred following inoculation of blossoms in host genotypes with and without $\mathrm{Sw}-5$. These results were further supported by field experiments that showed high proportions of infected fruit as well as a limited infection of foliage on the same stem as the infected fruit in Sw-5+ plants when $F$. occidentalis were abundant in blossoms. These findings help to explain observations of abundant late season infections of Sw-5 cultivars in commercial plantings and suggest that management of $F$. occidentalis infestations during the bloom period may be important for effective management of TSWV in susceptible tomato cultivars as well as cultivars expressing the $\mathrm{Sw}-5$ allele for TSW resistance.
\end{abstract}

Tomato spotted wilt (TSW) caused by Tomato spotted wilt virus (TSWV, genus Tospovirus, family Bunyaviridae) continues to threaten the production of many crops worldwide despite ongoing control efforts (Goldbach and Peters 1994; Pappu et al. 2009). At least nine species of thrips (family Thripidae) are known to transmit TSWV to over 1,000 plant species, including tomatoes, peppers, tobacco, and peanuts (Culbreath et al. 2003; Mound 1996; Parrella et al. 2003; Riley and Joseph 2011; Riley et al. 2011). Controlling the spread of TSW is challenging because immature thrips can acquire the virus from surrounding weed hosts and disperse into crops as adults, transmitting the virus for the duration of their lives (Groves et al. 2001, 2002; Ullman et al. 1997). Management techniques such as reflective mulch (Brown and Brown 1992; Greenough et al. 1990; Riley et al. 2012), applications of plant defense activators (Pappu et al. 2000), and use of pesticides (Brown and Brown 1992; Riley and Pappu 2000, 2004) have all shown limited success at controlling the disease when used singly (Cho et al. 1989; Momol et al. 2004; Reitz et al. 2003). The development of cultivars carrying a virus resistance gene is currently considered the most sustainable and effective single method for controlling TSW (Gordillo et al. 2008; Riley and Joseph 2011; Riley and Pappu 2004). The Sw-5 virus resistance allele was introgressed into commercial tomato cultivars to provide protection against TSW (Stevens et al. 1992, 1994). This single dominant allele belongs to a common family of disease resistance genes that encode nucleotide-binding site leucine-rich repeat (NBS$\mathrm{LRR}$ ) proteins. While the precise recognition mechanism is unknown, it is hypothesized that the $\mathrm{Sw}-5$ proteins act as inhibitors that recognize the virus and launch a signal transduction pathway causing a hypersensitive response at the site of inoculation, which prevents further spread of the virus to other cells (Brommonschenkel et al. 2000). TSWV isolates that induce this incompatible interaction in a resistant host are termed non-resistance-breaking (NRB). The Sw-5 allele has been very

${ }^{\dagger}$ Corresponding author: G. G. Kennedy; E-mail: gkennedy@ncsu.edu

*The $\boldsymbol{e}$-Xtra logo stands for "electronic extra" and indicates that one supplementary table and two supplementary figures are published online.

Accepted for publication 29 April 2017.

() 2017 The American Phytopathological Society effective in the greenhouse and field against most TSWV isolates (Boiteux and Giordano 1993; Gordillo et al. 2008; Riley and Joseph 2011). However, some isolates are able to overcome $\mathrm{Sw}-5$ due to genetic mutations (Hoffmann et al. 2001; López et al. 2011). These resistance-breaking (RB) isolates have emerged around the world and threaten the long-term durability of Sw-5 (Aramburu and Martí 2003; Cho et al. 1996; Ciuffo et al. 2005; Gordillo et al. 2008; Latham and Jones 1998).

A plant's ability to resist infection by TSWV is also affected by plant age. Even hosts without resistance alleles become progressively more resistant over time through a phenomenon called mature-plant resistance (Beemster 1958). In a study using TSW-susceptible bell peppers, susceptibility to TSW was measured in plants of different ages at the time they were first exposed to the virus through foliar inoculation using thrips. The incidence of infection in plants inoculated at the time of transplant and at 9 days post-transplant declined by $50 \%$ (Beaudoin et al. 2009). It has also been shown that later infections result in lower yield loss in tomato (Chaisuekul et al. 2003). Since plant susceptibility and yield loss decline rapidly with age, most control efforts are focused on protecting young plants during the period when they are highly susceptible to infection. However, mid- to late-season infections can result in major losses in crop production (Culbreath et al. 2003; Moriones et al. 1998).

In North Carolina, TSW poses a serious threat to tomato production. There are three known vectors of TSWV in the state: Frankliniella occidentalis (Pergande), F. fusca (Hinds), and Thrips tabaci. $F$. occidentalis is considered the most significant vector in tomato in many production areas (Cho et al. 1989; Eckel et al. 1996; German et al. 1992; Latham and Jones 1997; Pappu et al. 2009; Persley et al. 2006). Both adults and larvae can be abundant in the tight spaces within blossoms, developing fruit, and new growth, making them difficult to control with pesticides (Hansen et al. 2003). Under ideal conditions, $F$. occidentalis can develop from the egg to adult in 9 to 13 days, allowing for many generations in one season and rapid population growth and secondary spread of the virus (Katayama 1997; Lublinkhof and Foster 1977). Infections can lead to discoloration and deformity of the leaves and fruit, stunting, and even death of the plant (Cho et al. 1996). Many infections observed in resistant cultivars appear limited to the fruit (Aramburu and Rodriguez 1999). TSW symptoms have been observed in up to $90 \%$ of fruit produced in commercial plantings of resistant cultivars expressing the Sw-5 allele (Sw-5+) (G. G. Kennedy, unpublished). Occasionally, mild 
foliar symptoms surrounding infected fruit test positive for TSWV using DAS ELISA (J. L. Houle, personal observation). Frequent observations of $\mathrm{Sw}-5+$ plants expressing only symptomatic fruit late in the season led to the hypothesis that direct feeding on the fruit by viruliferous thrips can cause localized fruit infections in plants carrying Sw-5 (Aramburu and Rodriguez 1999). Aramburu et al. (2000) tested this hypothesis by placing viruliferous thrips on harvested, green fruit. The appearance of ringspots on several of the inoculated fruit confirmed this phenomenon. In the field, they observed $\mathrm{Sw}-5+$ plants with systemic infections at low titers, but attributed them to RB isolates or incomplete penetration of $\mathrm{Sw}-5$. Their study was limited to harvested fruit and did not consider the potential for disease progression within the plant if the fruits were infected while still on the plant. Furthermore, their study did not evaluate whether the Sw-5 resistance allele increases protection against infection by TSWV when fruit are fed upon by viruliferous thrips as compared with susceptible Sw-5- plants. Due to the frequent occurrence of infected fruit in Sw-5+ tomato plants, a better understanding is needed of the types of transmission events that result in symptomatic, infected fruit and associated yield losses, so that they can be more effectively managed.

Our study examines the question of whether feeding by viruliferous $F$. occidentalis on blossom clusters or very young fruit of $\mathrm{Sw}-5+$ tomato plants can lead to symptomatic TSWV-infected fruit. Herein, we test the hypothesis that inoculation of NRB isolates of TSWV by $F$. occidentalis feeding on blossoms or very young fruit results in infection of the developing fruit in both Sw-5+ and Sw-5- plants. We also test the hypothesis that systemic infections develop in host genotypes with and without the $\mathrm{Sw}-5$ resistance allele following inoculation of blossom or young fruit tissues by $F$. occidentalis.

\section{Materials and Methods}

Plants. Greenhouse and field experiments used Solanum lycopersicum cultivars Mountain Glory and Mountain Spring (Clifton Seeds, Faison, NC). Mountain Glory (Sw-5+) contains the $\mathrm{Sw}-5$ allele for resistance and Mountain Spring ( $\mathrm{Sw}-5-)$ lacks the $\mathrm{Sw}-5$ allele for resistance against TSWV.

Thrips. A virus-free lab colony of $F$. occidentalis was maintained on Phaseolus vulgaris bean pods at ca. $26^{\circ} \mathrm{C}, 55 \% \mathrm{RH}$, and continuous light. To obtain viruliferous adults used for TSWV transmission, neonate $(<3 \mathrm{~h}$ post-eclosion) $F$. occidentalis were placed on excised symptomatic Emilia sonchifolia leaves infected with one of the three field-collected NRB TSWV isolates (see below). The leaves and thrips were maintained inside a $50 \mathrm{~mm}$ diameter $\times$ 9 mm Parafilm-sealed Petri dish (Fisher Scientific, Pittsburgh, PA) containing moist filter paper and placed in an incubator for a 48 to $72 \mathrm{~h}$ acquisition-access period at $30^{\circ} \mathrm{C}$. The thrips were then transferred onto $P$. vulgaris bean pods in plastic containers with thripsproof mesh tops and bottoms, reared to adult, and used in the thrips inoculation experiments.

Verification that TSWV isolates were non-resistance breaking. Three TSWV isolates (designated Cart10, John10a, and John11) were collected from TSW-susceptible cultivars in commercial tomato plantings in Moore and Montgomery counties in North Carolina. These isolates were mechanically inoculated into $E$. sonchifolia and maintained in thrips-proof cages in a greenhouse. The isolates were initially tested for the ability to break Sw-5 resistance by mechanically inoculating into the foliage of tomato seedlings (two true leaves) of both Mountain Glory and Mountain Spring. Inoculum was prepared by grinding infected leaf tissue from E. sonchifolia in a chilled buffer containing $10 \mathrm{mM}$ Tris $\cdot \mathrm{HCl}(\mathrm{pH} 7.8), 10 \mathrm{mM} \mathrm{Na} \mathrm{SO}_{3}$, and $0.1 \%$ L-cysteine. All fully expanded leaves were coated with 600-mesh carborundum and gently rubbed using a cotton swab saturated with inoculum. Sw5+ and Sw-5- tomato seedlings were inoculated with each TSWV isolate prior to the experiment to test for $\mathrm{RB}$. None of the $\mathrm{Sw}-5+$ plants became systemically infected by any of the isolates (no. infected/no. plants inoculated: Cart10, 0/18; John10a, 0/22; John11, 0/24). The same inoculum from each isolate readily, systemically infected Sw-5- plants (Cart10, 12/20; John10a, 8/21; John11,13/24). To further confirm that isolates were NRB, thrips inoculations were conducted on Sw-5+ and Sw-5- seedlings using viruliferous adult $F$. occidentalis.
A subsample of 30 putatively viruliferous $F$. occidentalis adults were released onto 2- to 3-week-old Sw-5+ and Sw-5- tomato seedlings (one to two true leaves) growing in thrips-proof cages within a greenhouse in four separate experiments for a total of 45, 48, 49, and $48 \mathrm{Sw}-5+$ plants and 48, 46, 48, and $49 \mathrm{Sw}-5$ - plants for isolates Cart10, John10a, John 11, and John11, respectively. Thrips were allowed to feed for 1 week on seedlings before plants were sprayed with spinosyn insecticide to kill the thrips. Samples of newly emerged young leaves were collected 3 weeks after the thrips were released and tested for TSWV using double sandwich (DAS)ELISA for the nucleocapsid protein following the manufacturer's protocol (AGDIA, Elkhart, IN).

Transmission to reproductive tissue. One blossom cluster containing blossoms and/or blossoms with small developing fruit (ca. $2 \mathrm{~mm}$ diameter) per plant was enclosed in a thrips-proof cage constructed from 100 micron screen (Midwest Filter Corp, Lake Forest, IL). There was one cage per plant. A total of 46 plants had cages containing only blossoms at the time of thrips release and 12 plants had cages containing blossoms with small developing fruit when the thrips were released. Each cage was sealed around the peduncle of individual blossom clusters prior to blooming using putty (Oatey, Cleveland, $\mathrm{OH}$ ) or poster putty (Duck, Avon, $\mathrm{OH}$ ). All uncaged blossom clusters were regularly removed from the experimental plants before the flowers opened. Putatively viruliferous adult $F$. occidentalis (2 to 4 days post-eclosion) were released into each cage containing freshly opened flowers or newly set fruit per plant. Five to 10 thrips per individual blossom or fruit were released into an inflorescence cage containing 2 to 4 blossoms or fruit. A total of $33 \mathrm{Sw}-5+$ plants and $25 \mathrm{Sw}-5-$ plants were included in the experiment. TSWV isolate John10a was used to inoculate five $\mathrm{Sw}-5+$ and five $\mathrm{Sw}-5$ - plants, isolate Cart 10 to inoculate six Sw-5+ and five Sw-5- plants, and John 11 to inoculate $22 \mathrm{Sw}-5+$ and $15 \mathrm{Sw}-5-$ plants, respectively.

To minimize the risk of thrips escaping from the blossom cages and moving to other plants, each experimental plant was placed inside large thrips-proof enclosures $(0.76 \times 0.76 \times 1.22 \mathrm{~m})$ along with a yellow sticky trap to detect the presence of thrips outside of the blossom/fruit cages. To detect unintended virus spread, an indicator plant (E. sonchifolia) was also placed inside each enclosure and replaced every 2 weeks. No indicator plants developed infections and no $F$. occidentalis were caught on the yellow sticky traps or observed outside of the blossom cages. In addition, five TSWV- and thrips-free tomato plants of each genotype were placed randomly throughout the greenhouse as sentinels to detect virus spread within the greenhouse; none became infected by TSWV.

To determine if TSWV infections spread systemically from inoculated blossom clusters to noninoculated fruit, additional blossom clusters were enclosed in thrips-proof cages prior to the blossoms opening to exclude thrips. At least one blossom cluster was caged to exclude thrips prior to the thrips release into the other caged blossom cluster on the same plant. Additional blossom clusters that were initiated by the plant during weeks three and six following the thrips release were also caged to exclude thrips prior to the blossoms opening. All other blossoms were removed prior to opening. A systemic insecticide was added to the soil 5 to 7 days after the thrips release to kill all thrips for the remainder of the experiment.

To determine TSWV infection, tissue samples were collected from ripened fruit inside the blossom/fruit cages into which the thrips were released as well as from control cages that did not receive thrips. In addition, to determine if systemic spread of the infection had occurred, samples were taken of young leaf tissue produced on the same branch at the node immediately above and outside the blossom/fruit cage. Samples of young leaf tissue growing on other arbitrarily selected branches were also collected 3 weeks and 6 weeks after thrips were released into the blossom/fruit cages. These samples were tested for TSWV infection using DAS-ELISA. Samples were classified as TSWV-positive when the optical density exceeded the mean plus four standard deviations of the negative controls (three noninfected samples from same tissue type). Measurements were taken at $405 \mathrm{~nm}$ using a THERMOmax microtiter plate reader (Molecular Devices Corp., Menlo Park, CA). 
Analysis. The experiment was analyzed as a completely randomized design using logistic regression (Logistic Procedure, SAS v9.3, Cary, NC). Because an initial analysis revealed no significant effect of isolate on number of plants infected, isolate was not included in the analysis to test for significant effects of inoculation site (blossom only or blossom with small fruit at the time of thrips release), and genotype ( $\mathrm{Sw}-5+$ and $\mathrm{Sw}-5-)$ on the frequency of infections.

Field experiments. Small plot field experiments were conducted in 2011 and 2012 to monitor the prevalence of fruit-limited and systemic infections of TSWV in Mountain Glory (Sw-5+) and Mountain Spring (Sw-5-) plants. In both years, the experimental plantings were located in Candor, $\mathrm{NC}$, adjacent to a commercial planting of the TSW-resistant tomato cultivar Redline, which expresses the Sw-5 gene. Transplants were set in the field on 2 May 2011 and 16 May 2012. The Sw-5+ and Sw-5- treatments were included along with other tomato varieties in a larger randomized complete block experiment to evaluate varietal performance. Detailed data on TSW incidence were not collected from the other varieties; hence those varieties were not included in the analysis of results reported here. The 2011 experiments consisted of four replicates, each consisting of three plants of Mountain Spring ( $\mathrm{Sw}_{\mathrm{w}-5-}$ ) or Mountain Glory (Sw-5+) transplanted on 2 May. The 2012 experiment consisted of five replicates, each consisting of five $\mathrm{Sw}-5+$ plants and five Sw-5- plants transplanted on 16 May.

During both years, all plots were inspected at ca. 2-week intervals to identify TSWV-infected plants. To determine the presence of systemic infections, samples of young emerging leaf tissue were taken from each plant and subjected to DAS-ELISA. In 2011, samples were taken on 5 July and 25 August. In 2012, foliage samples were collected from plants with foliar or fruit symptoms every 2 weeks from 30 May through 31 July, at which time foliage from all plants not previously classified as infected was tested. In addition, during both years, symptomatic fruit were collected at the time that they were first observed and the plants from which they were collected were classified as either expressing or not expressing foliar symptoms. On 25 August 2011, all remaining fruit present on the surviving 10 Sw-5+ plants were removed and tested for infection using DAS-ELISA. In 2012, all fruit present on 30 July were collected from each plot and classified as TSWV-infected or noninfected based on presence or absence of symptoms and then subjected to DAS-ELISA to verify infection status and detect asymptomatic infections.

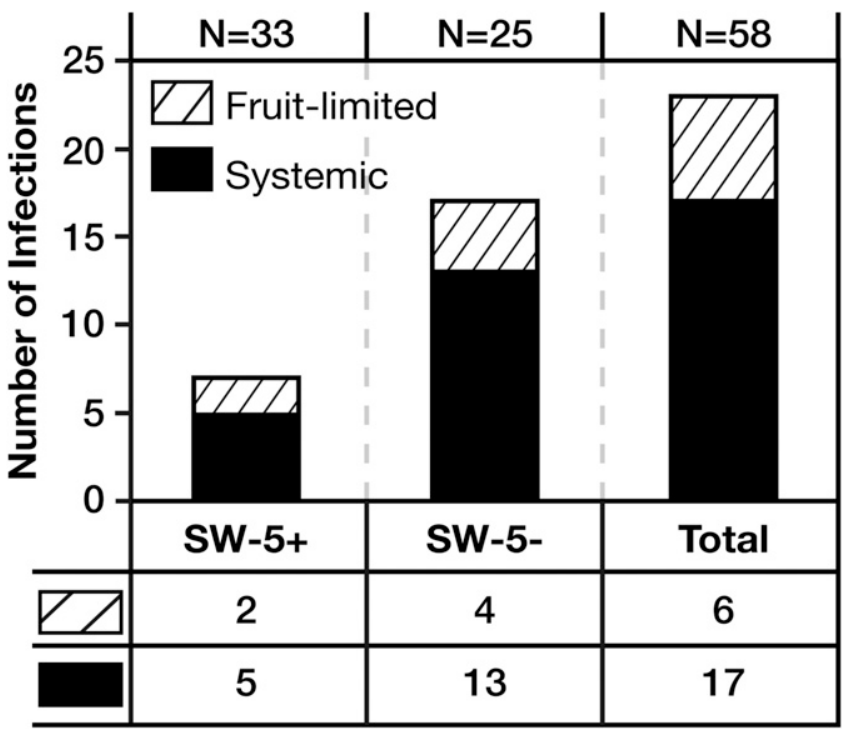

Fig. 1. Number of TSWV-infected plants following inoculation by $F$. occidentalis adults confined to blossoms of Sw-5+ and Sw-5- plants in greenhouse. Fruit-limited infections were detected only in fruit developing from blossoms exposed to viruliferous thrips. Systemic infections were infections that were detected in foliage and/or noninoculated fruit developing from blossoms that were caged prior to opening to exclude thrips. All infections were confirmed by DAS-ELISA. $\mathrm{N}=$ number plants exposed to viruliferous thrips.
The abundance of TSWV vectors in tomato blossoms was assessed during both years of the field trial. On each sample date, four to five samples each consisting of 10 blossoms selected arbitrarily across all cultivars were collected and placed in $70 \%$ ethanol. Samples were taken to the laboratory where the blossoms were dissected and all thrips counted. Adult thrips were slide-mounted and identified to species. In samples containing more than 25 thrips, a subsample of 25 were identified to species. In 2011, samples were collected on 14, 22 , and 30 June, and 22 July; in 2012, they were collected on 28 June and 17 and 30 July. Results are presented with standard errors.

\section{Results}

Verification that TSWV isolates were non-resistance breaking. In addition to the mechanical inoculation tests for RB, thrips inoculation tests were conducted to test if each isolate could infect systemically 2- to 3-week-old seedlings of $\mathrm{Sw}-5+$ and $\mathrm{Sw}-5-$ plants. No Sw-5+ seedlings became infected (no. infected/no. inoculated: 0/45, $0 / 48,0 / 49,0 / 48$ ) by any of the isolates, but each isolate was able to infect Sw-5- seedlings (28/48, 23/46, 32/48, 6/49) for experiments 1 (isolate John10a), 2 (isolate Cart10), and 3 and 4 (isolate John11), respectively.

Transmission to reproductive tissue. Transmission of TSWV to both $\mathrm{Sw}-5+$ and $\mathrm{Sw}-5$ - genotypes occurred when infectious thrips were caged on blossoms with or without visible, young fruit developing within the blossom (Fig. 1). Symptomatic fruit infections developed following inoculation by $F$. occidentalis confined to blossom clusters, as did systemic infections of noninoculated foliage and fruit of the same plant caged to exclude thrips. With the exception of two Sw-5+ and two Sw-5- plants, all systemic infections were observed on plants exhibiting infections at the site of inoculation (blossom clusters). In these cases, the blossoms exposed to viruliferous thrips failed to set fruit. Since extensive thrips feeding can cause flowers or fruit to abort (Childers 1997), it is possible that virus spread systemically from infected tissue that subsequently aborted. The number of infected plants, indicated by a positive DAS-ELISA test from any plant tissue, differed significantly between $\mathrm{Sw}-5+$ and $\mathrm{Sw}-5-$ hosts, with fewer infections among $\mathrm{Sw}-5+$ plants (7 of 33 plants) than among Sw-5- plants (17 of 25 plants) (odds ratio for transmission to $\mathrm{Sw}-5+$ versus $\mathrm{Sw}-5$ - plants $=0.116$ [95\% CI $0.033-0.405]$; Wald $\left.\mathrm{X}^{2}=11.42 ; \mathrm{df}=1 ; P=0.0007\right)$. The incidence of infected fruit did not differ significantly between treatments in which thrips were released on to blossoms with or without small developing fruit at the time of release (Wald $\mathrm{X}^{2}=2.272 ; \mathrm{df}=1 ; P=0.1318$ ) (Supplementary Table S1).

The frequency of infections that became systemic, confirmed by a positive DAS-ELISA test of leaf tissue or noninoculated fruit caged on the same plant to exclude thrips, was similar in both Sw-5+ and Sw-5- genotypes ( $71 \%$ and $76 \%$, respectively; Fig. 1). Of these systemic infections, nine resulted in infected fruit developing from blossoms that were caged prior to opening to exclude thrips and prevent any feeding on the blossoms. Three of these infections occurred on Sw-5+ and six on Sw-5- plants.

Typical symptoms of ringspots, necrosis, and abnormal growth were observed on the fruit (Supplementary Fig. S1). Symptom severity was in some cases extreme, causing fruit to wither and die. Foliar symptoms on blossom-inoculated Sw-5+ plants consisted of small necrotic lesions on leaves, generally one or two nodes above the inoculated blossom cluster; whereas symptoms on blossom-inoculated Sw-5- were characteristic of TSWV infections on tomato and consisted of chlorotic ringspots often surrounding small necrotic lesions.

Field experiments. In both years, TSWV infections were common, although less so in 2012. In 2011, all $10 \mathrm{Sw}-5+$ plants had at least some fruit that exhibited infection but none of the plants developed systemic infections. The mean percentage $( \pm \mathrm{SE})$ of infected fruit per Sw-5+ plant in 2011 was 38.9 (4.41). In 2012, seven of $25 \mathrm{Sw}-5+$ plants $(28 \%)$ were infected, six of which had infected fruit and three of which developed systemic infections. The mean percentage $( \pm$ SE) of infected fruit per Sw-5+ plant in 2012 was 12.1 (4.05), respectively. One of the $\mathrm{Sw}-5+$ plants became infected early in the season and developed symptoms typical of those observed in Sw- 
5- plants. The other two infections were detected late in the season and infections were limited to the infected fruit and foliage located directly above on the same branch (Supplementary Fig. S2). Because most of the Sw-5- plants were infected early and developed severe systemic infections, they produced few fruit. In 2011, all 12 Sw-5plants were systemically infected and produced no fruit. In 2012, 16 of $25 \mathrm{Sw}-5$ - plants $(64 \%)$ were systemically infected. Of these, only six of eight fruiting plants had symptomatic fruit. All field infections were confirmed by DAS-ELISA.

$F$. occidentalis was the predominant vector present during both years of the field experiment, comprising $89 \pm 6.5 \%$ of the thrips population within the blossoms in 2011 and $49 \pm 12.2 \%$ in 2012. The only other species present in the blossoms was $F$. tritici, a nonvector of TSWV. In 2011, F. occidentalis numbers remained high throughout the experiment, averaging $4.25 \pm 0.25$ adults per blossom, while in $2012, F$. occidentalis were less abundant, averaging $1.2 \pm 0.33$ adults per blossom (Fig. 2).

\section{Discussion}

Use of the Sw-5 resistance allele has provided significant protection in reducing losses to TSW (Riley and Joseph 2011; Riley and Pappu 2004); however, there are numerous reports of reduced efficacy due to occurrence of resistance-breaking (Aramburu and Martí 2003; Ciuffo et al. 2005; Latham and Jones 1998) and frequent reports of late-season expression of TSW symptoms in mature fruits of Sw-5+ tomato cultivars (Aramburu and Rodriguez 1999; Moriones et al. 1998). The failure of Sw-5 to prevent late-season fruit infections is poorly understood. This study extends previous research by Aramburu et al. (2000) demonstrating the ability of $F$. occidentalis to transmit TSWV to nearly mature excised fruit by demonstrating that fruit infections can result from feeding on blossoms by infectious $F$. occidentalis and that the $\mathrm{Sw}-5$ resistance allele can be circumvented by NRB isolates leading to systemic infections when inoculated into blossoms by $F$. occidentalis. The $\mathrm{Sw}-5$ resistance was effective at preventing infections resulting from inoculation of foliar tissue and reduced the probability of infection resulting from inoculation of blossoms and/or very small fruit relative to Sw-5- hosts in our experiments. Thrips transmission to blossoms apparently provides a gateway for NRB isolates of TSWV to infect Sw-5+ plants and move systemically.

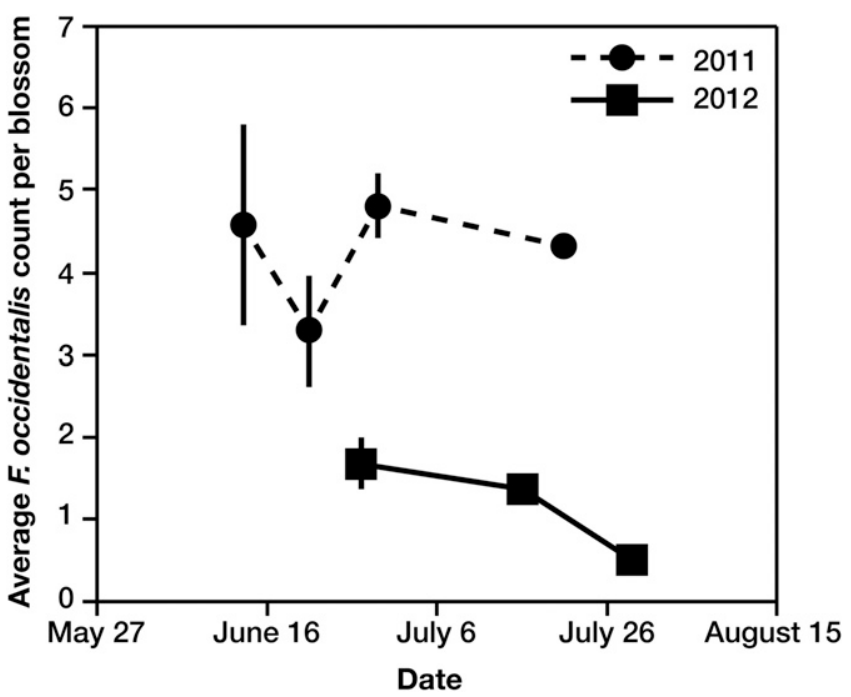

Fig. 2. Average number of Frankliniella occidentalis adults per blossom in 2011 and 2012. One hundred percent and $64 \%$ of Sw-5- plants were systemically infected with TSW in 2011 and 2012, respectively. The mean percentage of infected fruit per Sw-5+ plant in 2011 and 2012 was 38.9 and 12.1, respectively. Bars represent standard error. Due to a handling error, data points for 22 July 2011 and 17 July 2012 represent only a sample of 10 blossoms; hence standard error bars are not presented.
Systemic infections not attributed to resistance-breaking isolates have been considered to result from incomplete penetration of Sw-5, resulting in approximately $2 \%$ of plants becoming infected (Aramburu et al. 2000; Stevens et al. 1992). Our experiment revealed a much higher incidence of such infections. Although we found significantly fewer total infections (i.e., fruit limited, systemic, or both) of Sw-5- than Sw-5+ plants following thrips inoculation of blossoms/fruit, we did not detect a significant difference in incidence of systemic infections between Sw-5+ and Sw-5- plants. However, the numbers of infected $\mathrm{Sw}-5$ - plants were low (seven total, five systemic infections) compared with $\mathrm{Sw}-5+$ plants (17 total, 13 systemic infections) and it remains possible that additional replication to achieve higher incidences of total and systemic infections would reveal differences between the Sw-5+ and $\mathrm{Sw}-5-$ plants.

To ensure that our results were not unique to a specific TSWV isolate, we included different isolates that failed to infect $\mathrm{Sw}-5+$ plants following mechanical or thrips inoculation of foliar tissue and found that all were able to infect $\mathrm{Sw}-5+$ plants when inoculated by $F$. occidentalis into blossoms. In the field, we also observed infections of $\mathrm{Sw}-5+$ plants that were limited to foliage directly above symptomatic fruit. Several isolates collected from a grower's planting of the Sw-5+ cultivar Redline in Candor, NC, were tested for RB. Inoculations from Sw-5+ foliage were often unsuccessful. However, mechanical inoculations of foliage of Sw-5- Mountain Spring seedlings using isolates obtained from infected fruit from two Sw-5+ plants resulted in seven and two infected plants per 15 inoculated seedlings, respectively; similar inoculations of $\mathrm{Sw}-5-$ seedlings with an isolate obtained from infected foliage of a third $\mathrm{Sw}-5+$ plant resulted in nine infected plants per 24 inoculated seedlings. Mechanical inoculations of seedlings of 15,15 , and $24 \mathrm{Sw}-5+$ Mountain Glory plants using these isolates, respectively, failed to produce any infections. This suggests that the isolates infecting the resistant plants are unlikely to be resistance-breaking. One likely hypothesis explaining our results is that the Sw-5 gene is not expressed in blossoms and fruit.

In our field experiments, $F$. occidentalis was the only vector observed during the bloom period and was more abundant in 2011 when TSW prevalence was high than in 2012 when prevalence was low. This difference in vector abundance during the bloom period likely accounts for the differences in TSW prevalence between years. Previous studies have shown that while the tobacco thrips, $F$. fusca, is generally the primary vector of TSWV during the spring (April through early June), F. occidentalis is the primary vector during the summer months (Beaudoin 2011). Our results suggest that controlling $F$. occidentalis populations throughout the season to prevent populations from developing in the blossoms and feeding on newly set fruit may prove important in reducing late-season spread and prevalence of infected fruits in Sw-5+ varieties. Although tomato plants that become infected later in the season produce significantly more fruit than plants infected early, the fruits often express symptoms of infection and are unmarketable (Moriones et al. 1998). A further concern when thrips populations develop within a planting is the potential for secondary spread. Since immature $F$. occidentalis can be found consistently in tomato blossoms throughout the season (Beaudoin 2011), and have been shown to acquire TSWV from infected tomato fruits and subsequently transmit it to susceptible plants (Szostek et al. 2017), it may be possible for them to acquire TSWV and spread it among fruit clusters within a field of $\mathrm{Sw}-5+$ plants, even in the absence of systemic infection.

\section{Acknowledgments}

This work was supported by USDA CSREES Risk Avoidance and Mitigation Program Grant \# RF330-411-3843858 and USDA NIFA Coordinated Agricultural Project Grant 2012-68004-20166, and a National Science Foundation Graduate Research Fellowship awarded to J. L. Houle. Thanks to D. Grist for thrips identification, T. Chappell for assistance with data analysis, and A. L. Jacobson and D. D'Ambrosio for comments on earlier drafts of the manuscript.

\section{Literature Cited}

Aramburu, J., and Martí, M. 2003. The occurrence in north-east Spain of a variant of Tomato spotted wilt virus (TSWV) that breaks resistance in tomato (Lycopersicon esculentum) containing the Sw-5 gene. Plant Pathol. 52:407. 
Aramburu, J., and Rodriguez, M. 1999. Evaluation of commercial Lycopersicon esculentum hybrids for resistance to tomato spotted wilt tospovirus (TSWV) in Spain. J. Hortic. Sci. Biotechnol. 74:743-747.

Aramburu, J., Rodriguez, M., and Ariño, J. 2000. Effect of Tomato spotted wilt tospovirus (TSWV) infection on the fruits of tomato (Lycopersicon esculentum) plant of cultivars carrying the SW-5 gene. J. Phytopathol. 148:569-574.

Beaudoin, A. L. P. 2011. Temporal and spatial patterns of thrips dispersal in relation to the epidemiology of Tomato spotted wilt virus. PhD dissertation, Order No. 3497228, North Carolina State University. Retrieved from ProQuest Dissertations and Theses.

Beaudoin, A. L. P., Kahn, N. D., and Kennedy, G. G. 2009. Bell and banana pepper exhibit mature-plant resistance to Tomato spotted wilt tospovirus transmitted by Frankliniella fusca (Thysanoptera: Thripidae). J. Econ. Entomol. 102:30-35.

Beemster, A. B. R. 1958. Some aspects of mature plant resistance to viruses in the potato. Pages 212-217 in: Proceedings of the Third Conference on Potato Virus Diseases, 24-28 June 1957, Lisse-Wageningen, The Netherlands. F. Quak, J. Dijkstra, A. B. R. Beemster, and J. P. H. van der Want, eds. H. Veenman and Zonen, Wageningen, The Netherlands.

Boiteux, L. S., and Giordano, L. de B. 1993. Genetic-basis of resistance against 2 tospovirus species in tomato (Lycopersicon esculentum). Euphytica 71:151-154.

Brommonschenkel, S. H., Frary, A., Frary, A., and Tanksley, S. D. 2000. The broad- spectrum tospovirus resistance gene $\mathrm{Sw}-5$ of tomato is a homolog of the root-knot nematode resistance gene Mi. Mol. Plant Microbe Interact. 13:1130-1138

Brown, S. L., and Brown, J. E. 1992. Effect of plastic mulch color and insecticides on thrips populations and damage to tomato. HortTechnology 2:208-211.

Chaisuekul, C., Riley, D. G., and Pappu, H. R. 2003. Transmission of Tomato spotted wilt virus to tomato plants of different ages. J. Entomol. Sci. 38:127-136.

Childers, C. C. 1997. Feeding and oviposition injuries to plants. Pages 505-537 in: Thrips as Crops Pests. T. Lewis, ed. CAB International, New York.

Cho, J. J., Custer, D. M., Brommonschenkel, S. H., and Tanksley, S. D. 1996. Conventional breeding: host-plant resistance and the use of molecular markers to develop resistance to tomato spot wilt virus in vegetables. Acta Hortic. 431:367-378.

Cho, J. J., Mau, R. F. L., German, T. L., Hartmann, R. W., Yudin, L. S., Gonsalves, D., and Provvidenti, R. 1989. A multidisciplinary approach to management of tomato spotted wilt virus in Hawaii. Plant Dis. 73:375-384.

Ciuffo, M., Finetti-Sialer, M. M., Gallitelli, D., and Turina, M. 2005. First report in Italy of a resistance-breaking strain of Tomato spotted wilt virus infecting tomato cultivars carrying the Sw5 resistance gene. Plant Pathol. 54:564.

Culbreath, A. K., Todd, J. W., and Brown, S. L. 2003. Epidemiology and management of tomato spotted wilt in peanut. Annu. Rev. Phytopathol. 41:53-75.

Eckel, C. S., Cho, K., Walgenbach, J. F., Kennedy, G. G., and Moyer, J. W. 1996. Variation in thrips species composition in field crops and implications for tomato spotted wilt epidemiology in North Carolina. Entomol. Exp. Appl. 78:19-29.

German, T. L., Ullman, D. E., and Moyer, J. M. 1992. Tospoviruses: Diagnosis, molecular biology, phylogeny and vector relationships. Annu. Rev. Phytopathol. 30:315-348.

Goldbach, R., and Peters, D. 1994. Possible causes of the emergence of tospovirus diseases. Semin. Virol. 5:113-120.

Gordillo, L. F., Stevens, M. R., Millard, M. A., and Geary, B. 2008. Screening two Lycopersicon peruvianum collections for resistance to Tomato spotted wilt virus. Plant Dis. 92:694-704.

Greenough, D. R., Black, L. L., and Bond, W. P. 1990. Aluminum-surfaced mulch: An approach to the control of tomato spotted wilt virus in solanaceous crops. Plant Dis. 74:805-808.

Groves, R. L., Walgenbach, J. F., Moyer, J. W., and Kennedy, G. G. 2001. Overwintering of Frankliniella fusca (Thysanoptera: Thripidae) on winter annual weeds infected with Tomato spotted wilt virus and patterns of virus movement between susceptible weed hosts. Phytopathology 91:891-899.

Groves, R. L., Walgenbach, J. F., Moyer, J. W., and Kennedy, G. G. 2002. The role of weed hosts and tobacco thrips, Frankliniella fusca, in the epidemiology of Tomato spotted wilt virus. Plant Dis. 86:573-582

Hansen, E. A., Funderburk, J. E., Reitz, S. R., Ramachandran, S., Eger, J. E., and McAuslane, H. 2003. Within-plant distribution of Frankliniella species
(Thysanoptera: Thripidae) and Orius insidiosus (Heteroptera: Anthocoridae) in field pepper. Environ. Entomol. 32:1035-1044.

Hoffmann, K., Qiu, W. P., and Moyer, J. W. 2001. Overcoming host- and pathogen-mediated resistance in tomato and tobacco maps to the M RNA of Tomato spotted wilt virus. Mol. Plant Microbe Interact. 14:242-249.

Katayama, H. 1997. Effect of temperature on development and oviposition of western flower thrips Frankliniella occidentalis (Pergande). J. Appl. Entomol. Zool. 41:225-231

Latham, L. J., and Jones, R. A. C. 1997. Occurrence of tomato spotted wilt tospovirus in native flora, weeds, and horticultural crops. Aust. J. Agric. Res. 48:359-369.

Latham, L. J., and Jones, R. A. C. 1998. Selection of resistance breaking strains of Tomato spotted wilt tospovirus. Ann. Appl. Biol. 133:385-402.

López, C., Aramburu, J., Galipienso, L., Soler, S., Nuez, F., and Rubio, L. 2011. Evolutionary analysis of tomato $\mathrm{Sw}-5$ resistance-breaking isolates of Tomato spotted wilt virus. J. Gen. Virol. 92:210-215.

Lublinkhof, J., and Foster, D. E. 1977. Development and reproductive capacity of Frankliniella occidentalis (Thysanoptera: Thripidae) reared at three temperatures. J. Kans. Entomol. Soc. 50:313-316.

Momol, M. T., Olson, S. M., Funderburk, J. E., Stavisky, J., and Marois, J. J. 2004 Integrated management of tomato spotted wilt on field-grown tomatoes. Plant Dis. $88: 882-890$

Moriones, E., Aramburu, J., Riudavets, J., Arnó, J., and Laviña, A. 1998. Effect of plant age at time of infection by tomato spotted wilt tospovirus on the yield of field-grown tomato. Eur. J. Plant Pathol. 104:295-300.

Mound, L. A. 1996. The Thysanoptera vector species of Tospoviruses. Acta Hortic. 431:298-309.

Pappu, H. R., Csinos, A. S., McPherson, R. M., Jones, D. C., and Stephenson, M. G. 2000. Effect of acibenzolar-S-methyl and imidacloprid on suppression of tomato spotted wilt Tospovirus in flue-cured tobacco. Crop Prot. 19:349-354.

Pappu, H. R., Jones, R. A. C., and Jain, R. K. 2009. Global status of tospovirus epidemics in diverse cropping systems: Successes achieved and challenges ahead. Virus Res. 141:219-236.

Parrella, G., Gognalons, P., Gebre-Selassiè, K., Vovlas, C., and Marchoux, G. 2003. An update of the host range of Tomato spotted wilt virus. J. Plant Pathol. 85:227-264.

Persley, D. M., Thomas, J. E., and Sharman, M. 2006. Tospoviruses-an Australian perspective. Australas. Plant Pathol. 35:161-180.

Reitz, S. R., Yearby, E. L., Funderburk, J. E., Stavisky, J., Momol, M. T., and Olson, S. M. 2003. Integrated management tactics for Frankliniella thrips (Thysanoptera: Thripidae) in field-grown peppers. J. Econ. Entomol. 96: 1201-1214

Riley, D. G., and Joseph, S. V. 2011. Host plant resistance to Tomato spotted wilt virus (Bunyaviridae: Tospovirus) in tomato. HortScience 46:1626-1633.

Riley, D. G., Joseph, S. V., and Srinivasan, R. 2012. Reflective mulch and acibenzolar-S-methyl treatments relative to thrips (Thysanoptera: Thripidae) and Tomato spotted wilt virus incidence in tomato. J. Econ. Entomol. 105: 1302-1310.

Riley, D. G., Joseph, S. V., Srinivasan, R., and Diffie, S. 2011. Thrips vectors of Tospoviruses. J. Integr. Pest Manag. 2:I1-I10.

Riley, D. G., and Pappu, H. R. 2000. Evaluation of tactics for management of thrips-vectored Tomato spotted wilt virus in tomato. Plant Dis. 84:847-852.

Riley, D. G., and Pappu, H. R. 2004. Tactics for management of thrips (Thysanoptera: Thripidae) and Tomato spotted wilt virus in tomato. J. Econ. Entomol. 97:1648-1658.

Stevens, M. R., Scott, S. J., and Gergerich, R. C. 1992. Inheritance of a gene for resistance to Tomato spotted wilt virus (TSWV) from Lycopersicon peruvianum Mill. Euphytica 59:9-17.

Stevens, M. R., Scott, S. J., and Gergerich, R. C. 1994. Evaluation of 7 Lycopersicon species for resistance to tomato spotted wilt virus (TSWV). Euphytica 80:79-84

Szostek, S. A., Rodriguez, P., Sanchez, J., Adkins, S., and Rayapati, N. A. 2017. Western flower thrips can transmit Tomato spotted wilt virus from virusinfected tomato fruits. Plant Health Prog. 18:1-6.

Ullman, D. E., Sherwood, J. L., and German, T. L. 1997. Thrips as vectors of plant pathogens. Pages 539-564 in: Thrips as Crop Pests. T.Lewis, ed. CAB International, Wallingford, U.K 